\title{
A IMPORTÂNCIA DA FAMÍLIA E SUAS RELAÇÕES: UM ESTUDO DE CASO
}

\section{The importance of the family and its relations: a case study}

\author{
Daiana de Souza Milani ${ }^{1}$ \\ Daniele Bezerra Rodrigues ${ }^{2}$ \\ Renate Brigitte Vicente ${ }^{3}$
}

\section{Resumo}

Este artigo tem a finalidade de expor um estudo de caso a partir da abordagem sistêmica de Palo Alto, relatando um casal que busca atendimento psicológico para uma de suas filhas, porém, a partir da queixa inicial percebe-se que o casal discute a sua própria relação. A partir disso, mostra-se os objetivos de uma terapia familiar sistêmica e os métodos utilizados, bem como o papel do psicólogo nesse processo. 0 principal requisito é o reenquadramento, mudando-se o foco da família que centra sua atenção no paciente trazido à sessão e considera seu problema como uma fraqueza individual, para uma visão na qual se considere as redes de relacionamento, suas formas de adaptação e falhas de comunicação.

Palavras-chave: Terapia infantil; Terapia familiar sistêmica; Caso clínico.

\section{Abstract}

This essay has the goal to exhibit a case study of the systemic approach by Palo Alto, it describes a couple that look for a psychological assistant for one of their daughters, however after the initial complaint we realized that the couple discuss their own relation. After this we show the objective of a family therapy and the methods used, as well as the role of the psychologist in this process. The main requisite is re-squaring, then we change the family focus which center their attention in the patient that was brought to the session and her problem that is consider by the family as a personal weakness, to a new view that consider the relationship nets, their mode of adaptation and fault of communication.

Keywords: Childish therapy; Family therapy; Clinical case.

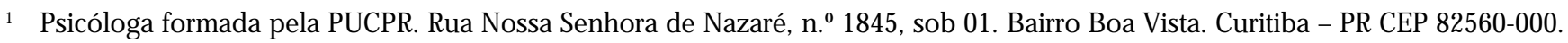
E-mail: daiana_milani@yahoo.com.br

2 Psicóloga formada pela PUCPR. Rua José Palu, n.ํㅡㄴ 683, bloco 1, ap 303. Bairro Novo Mundo. Curitiba - PR CEP $81020-050$. E-mail: dani.dbr@gmail.com

3 Psicóloga, Professora do curso de Psicologia da PUCPR, Mestre em Educação pela UFPR. E-mail: renate.vicente@pucpr.br 
O presente artigo trata-se de um estudo de caso ${ }^{4}$ analisado a partir da abordagem sistêmi$\mathrm{ca}^{5}$, especificamente a partir da escola de Palo Alto. Neste estudo serão utilizados nomes fictícios para facilitar a interpretação e reflexão sobre o caso clínico. Especificamente, o caso se refere a uma família que traz como queixa à terapia a quarta filha do casal - Jaqueline. Ela era a penúltima filha, de um total de cinco filhos. Atualmente tem quatro anos de idade e a queixa era direcionada à dificuldade alimentar da criança.

Sabe-se pelos dados do caso que quando ocorreu a gestação de Jaqueline, sua mãe, que denominaremos de Ana, estava muito preocupada com a sua vida profissional e não desejava ter mais filhos. Seu desejo era permanecer apenas com os seus três filhos já existentes. Após a gravidez de Jaqueline, Ana passou por um período de depressão pós-parto, o que levou a sua separação da criança. Quando a menina completa seis meses de idade, Ana reintegra-se ao lar e retoma a sua vida profissional, mas pouco tempo depois engravida novamente. Então, por sua decisão, seus dois filhos mais novos ficaram morando com uma babá e eventualmente visitam a mãe. Ana vive em uma cidade isolada e possui um marido ausente, que só vai a casa duas vezes por semana.

Jorge, o pai das crianças, é órfão desde muito cedo, sendo muito amoroso especialmente com Jaqueline, fazendo tudo que ela quer. Ele teve uma infância infeliz, com a perda de um pai e de uma tia inválida que ocupou o lugar de uma mãe pouco afetuosa. Jorge relata censurar sua esposa por não amar seus filhos e não dar a devida atenção quando estes os vêem visitá-los. Sente que sua mulher é uma mãe má por não querer nunca mais ter filhos - a exemplo de sua própria mãe. Para ele, foi Jaqueline quem provocou a desunião do casal.

Sob o foco da abordagem sistêmica e com articulação teórica de Palo Alto, compreende-se que o casal vem à terapia a partir de uma queixa inicial em relação à Jaqueline, ou seja, ela é o pa- ciente identificado (PI) ${ }^{6}$. Entretanto, a partir da discussão do casal sobre sua filha, eles se permitem discutir sobre sua relação conjugal. Com a proposta teórica, entende-se que a comunicação é o ponto ênfase, ou seja, propõe mudar a pauta comunicacional entre os membros a fim de alterar o sintoma, não focalizando a terapia no PI e nos determinismos intrapsíquicos, mas sim na rede relacional da pessoa ou do sistema familiar.

Durante o desenvolvimento humano, em determinadas fases da vida, como a infância, adolescência, fase adulta e idosa, ocorrem algumas crises características de tais fases, sendo essas consideradas "comuns e normais". Entretanto, a maneira como cada pessoa age e lida com tais circunstâncias irá variar conforme a singularidade e personalidade de cada um.

Na fase adulta, por exemplo, com o advento do casamento, ocorre uma série de expectativas em relação à nova família, principalmente se a esposa trabalha fora. Há preocupações quanto à renda familiar, aquisição de novos bens, manutenção da casa, etc. Com a gravidez, fase de extrema importância e significação para o casal, principalmente para a mulher, há várias modificações nesse sistema familiar. Inicia-se a preocupação com a criança que está por vir e um questionamento pessoal se os cônjuges conseguirão desempenhar a função materna e paterna, juntamente com as funções de manutenção de seu lar. Cada cônjuge, geralmente, começa a assumir o papel que lhe é imposto socialmente, sendo necessário que o casal esteja apto a enfrentar tais modificações e, conseqüentemente, as cobranças que lhes são impostas. Carter e Mc Goldrick (1995, p. 208) explicam que a herança herdada ao longo dos tempos, com relação aos papéis sociais e as tradições quanto ao gênero masculino e feminino, faz parecer que constituam a base pela qual cada pessoa organiza seu relacionamento e distribui as responsabilidades da educação dos filhos e do ganho de dinheiro.

Se retomarmos o contexto histórico, é possível fazer um paralelo entre a relação pai-fi-

4 Este caso está narrado e estudado de forma psicanalítica por Maud Mannoni na obra Primeira Entrevista em Psicanálise. A criança tem o nome de "Noele".

5 Este caso foi um dos casos trabalhados no PA Laboratório de Práticas no Contexto Clínico na PUCPR (Psicologia) pelos professores: Marisa S. Silva, Renate B. Vicente, Cloves Amorim, Rosa M. M. Mariotto e Jussara Carvalho, nas perspectivas psicodramáticas, sistêmica, comportamental, psicanalítica e analítica junguiana.

6 PI significa paciente identificado - o bode expiatório da família, ou seja, aquele que apresenta sintomas de perturbação física e/ou psíquica. A abordagem sistêmica acredita que o psiquismo de um indivíduo não é apenas um fenômeno interno, mas oriundo de um processo interpessoal, isto é, diretamente envolvido e modificado pela interação com o seu ambiente. 
lho e senhor-escravo. O pai tinha todo o poder sobre os filhos, da mesma forma que o senhor sobre seus escravos. Eles lhe pertenciam como se fosse uma propriedade (simplesmente porque eles os fizeram), porém não deviam nada a eles. Com o passar do tempo, essa visão passou a ser modificada. Na sociedade contemporânea, o fato dos pais serem os procriadores de seus filhos conferelhes mais deveres do que, propriamente dito, direitos sobre eles. (Flandrin in Ponciano \& FéresCarneiro, 2003, p. 60).

Após a Segunda Guerra Mundial houve a necessidade das mulheres se inserirem no mercado de trabalho. Entretanto, mesmo trabalhando fora, as atividades domésticas ainda lhe são atribuídas. A busca de igualdade entre homens e mulheres fica bem distante no nascimento de um filho, pois ainda cabe à mãe a administração da casa e o cuidado do bebê. A sociedade ainda espera que a mulher abra mão de sua vida profissional e de sua independência para cuidar de seu filho e manter o seu lar. O nascimento de um filho envolve questões como o espaço que a criança irá ocupar na família e se ele é ou não objeto de desejo dos pais. É preciso que o bebê seja desejado, amado e bem vindo pelos seus pais, mesmo trazendo consigo várias modificações na estrutura familiar. Necessita de dedicação, atenção, cuidado, zelo, etc. Tais aspectos influenciam na relação conjugal, pois, muitas vezes, com a chegada do filho, inicia-se uma experiência do cônjuge sentirse ignorado, isolado e, principalmente a mãe, sobrecarregada com a maior complexidade das tarefas e relacionamentos, impedindo a privacidade do casal, e principalmente na intimidade sexual.

De maneira unânime, no casamento, cada cônjuge começa a atuar conforme os seus padrões e valores preestabelecidos, com as aprendizagens adquiridas desde a infância na sua família de origem, nos relacionamentos interpessoais, nos convívios familiares e também influenciados por características culturais. Cada um traz consigo as suas expectativas e sua forma de avaliar o mundo e precisam adequar às duas diferentes formas de vida na nova família que está sendo constituída. No caso exemplificado percebe-se que Ana vivencia um conflito em se dedicar à família e ter um espaço para si, o que acarreta em pressões sociais para que ela aja de acordo com que é esperado pelos valores sociais, ou seja, cuidar de seus filhos. Quanto a Jorge, nota-se que ele faz parte dessa pressão so cial para com a mãe, cobrando dela a obrigação do amor materno. Mas por sua história de vida ele também repete o sistema familiar de seus pais, onde existia uma mulher má e um pai bonzinho e ausente. Satir (1980, p. 49 a 51) ilustra tal questão familiar quando afirma que a revolução industrial afetou diretamente a vida das pessoas, principalmente na família moderna. De maneira ambivalente, simultaneamente eliminou certas sobrecargas (o homem deixa de ser o chefe da casa e a mulher a única responsável pela administração do lar e da criação dos filhos) e passou a inserir novas tensões e preocupações, com relações aos novos papéis e funções delimitadas.

De acordo com Ponciano (2002) os pais assumem a responsabilidade do amor e do poder sobre o filho. Cada atitude voltada para a criança transmite-lhe as normas, regras e valores estabelecidos pela sociedade, muitas vezes de maneira indireta e independente de suas intenções. A manifestação da cultura se dá involuntariamente, pois se estabelece na constituição da personalidade do sujeito, sendo transferida de geração a geração.

O nascimento de Jaqueline trouxe a tona questões importantes que estavam mal resolvidas, como às expectativas de vida de sua mãe e problemas de relacionamento entre a família de seu pai. Tanto Ana quanto o Jorge uniram-se sem flexibilizar os seus próprios valores. Trouxeram as suas expectativas e experiências anteriores sem planejarem e estabelecerem objetivos em comum. Ficaram próximos um do outro, porém não havia intimidade e a cumplicidade necessária para um relacionamento saudável e adequado. Os pais utilizam Jaqueline para trabalhar os seus próprios problemas, isto é, a criança está como intermediária nessa relação, porém de maneira inconsciente. É como se até este momento tal família fosse como um vulcão adormecido e a gravidez culminou a erupção. Com isso houve a quebra da homeostase existente até o momento.

A família é o agente transmissor da cultura, bem como a responsável pela consolidação de tais características na personalidade do sujeito. Para que isso ocorra é preciso haver duas fontes de tensão: uma originada da nova relação com a infância e a outra de uma transformação no papel feminino. A partir do século XIX passam a haver mudanças, pois os papéis masculinos e femininos existentes até 0 momento não se enquadram mais ao que está sendo exigido de ambos após as mu- 
danças tecnológicas/industriais. A criança passa a ser de responsabilidade dos pais, gerando uma sobrecarga. Com relação à mulher, anteriormente era educada para criar seus filhos, precisando ser companheira de seu marido e executar as tarefas domésticas. Com o feminismo passa a ocorrer uma "desordem", surgindo novas aspirações ao crescimento pessoal e posteriormente profissional. A estas aspirações a união conjugal e a família não podiam mais satisfazer, gerando uma crise no casamento (Ponciano \& Féres-Carneiro, 2003, p. 62).

Por outro lado, Bradt in Carter e Mc Goldrick (1995, p. 213; 215) afirma que o fracasso de qualquer um dos cônjuges, na execução de seus papéis conjugais e parentais, contribui para a desigualdade dos relacionamentos e ameaçam a intimidade do casal. Quando há intimidade num casamento é possível acertar no desafio que a paternidade estabelece, integrando adequadamente as mudanças ocorridas. Para isso é preciso haver um reequilíbrio das responsabilidades do marido e da mulher. Em algumas famílias passa a ocorrer da mulher deixar de trabalhar fora. No caso exemplificado, os pais de Jaqueline dizem estar separados, porém ainda estão muito ligados e preocupados com a maneira como cada um se comporta. Eles estão próximos, mas não possuem intimidade. Relacionam-se com críticas e trocas de ofensas, não conseguindo crescer nessa relação. Dessa forma, sentem dificuldades para se adaptarem às mudanças surgidas pelo nascimento de um novo filho.

Ainda segundo os mesmos autores (1995, p. 206), não há nenhum estágio no desenvolvimento humano que ocasione tantas alterações e de significado tão profundo quanto uma gestação. Ser um progenitor resulta em vencer um grande desafio, é resultante de interações biopsicossociais, bem como de modificação da homeostase no trabalho, no relacionamento com amigos e familiares. Socialmente é exigido da mãe o cuidado pela criança. Sua intenção de retornar ao mercado de trabalho e reencontrar-se como pessoa torna-se um ponto crítico e decisivo no âmbito familiar. A motivação que a leva tentar recuperar o seu eu e readequar os seus relacionamentos adultos, muitas vezes, é a responsável por inúmeros conflitos. Os maiores estresses são experimentados pelos pais que tentam coordenar os seus respectivos empregos com a responsabilidade da administração da casa e do cuidado com os filhos. Percebe-se que na relação familiar, no caso citado, os pais de Jaqueline mantêm suas fronteiras ${ }^{7}$ tendendo ao fechamento, não havendo trocas e crescimento, as quais possibilitam a manutenção da identidade do grupo, lealdade e sigilo. Além disso, há uma relação simétrica ${ }^{8}$ entre o casal, que se baseia na igualdade, ou seja, tanto Jorge quanto Ana estão com suas preocupações voltadas a si próprios, não estabelecendo uma relação de intimidade e proximidade conjugal.

É preciso perceber o ambiente em que as crianças nascem, podendo este ser determinado por inúmeros fatores. Pode existir ou não espaço para elas (pode já estar sendo preenchido por outros relacionamentos ou atividades) ou apenas existir um vácuo que devam preencher (Bradt in Carter \& Mc Goldrick, 1995, p. 210). Quando se percebe que uma criança está sendo usada indiretamente e de maneira disfuncional deve-se questionar qual dos filhos o casal escolhe inconscientemente para servir aos propósitos do PI e se esse filho mantém tal papel e função. Deve-se estar atento para a posição desse filho na família, bem como o seu sexo e idade e as diferentes características de todos os filhos. Tais características podem induzir conflitos no casal e a disponibilidade do filho de exercer o papel de PI (Satir, 1980, p. 6165), pois cada uma dessas características interage diferentemente no casal, nas suas funções parentais, correspondendo ou não as expectativas construídas.

Bradt in Carter e Mc Goldrick (1995, p. 211; 220) defende a idéia de que a intensidade da preocupação dos pais com uma criança tem duas origens: primeiramente é o relacionamento histórico ou atual de cada progenitor com seus pais e posteriormente é a fragilidade nos diferentes relacionamentos interpessoais (cônjuge, familiares, amigos). Ana soube agir com habilidade até o terceiro filho, rejeitando a gravidez e a criação de Jaqueline. Ela assumiu esse papel de "mãe má"

\footnotetext{
7 Fronteiras são regras internalizadas que direcionam as formas de funcionamento dos sistemas e subsistemas, estabelecendo quem são os seus membros. Tem como função a proteção e diferenciação dos indivíduos.

8 É caracterizada uma relação simétrica quando os cônjuges tendem a refletir sobre as atitudes si e do outro, buscando melhorias no relacionamento
} 
desde o princípio e o marido apresentou uma identificação com a filha, com sua história de vida, principalmente no que tange à rejeição. No entanto, Jorge diz que ama Jaqueline, porém não a levou para morar consigo durante a separação decorrente da depressão pós-parto, e ainda a culpa pelo fim de seu casamento. Surge aí uma mensagem antagônica, ou seja, um sistema familiar disfuncional, hipotetizando-se o estabelecimento do duplovínculo ${ }^{9}$. Satir (1980, p. 79; 93) afirma que muitas vezes os casais acham que as funções parentais não são influenciadas pelo seu próprio relacionamento conjugal problemático. Os pais disfuncionais não têm consciência do fato de que estão destruindo com uma mão aquilo que constroem com a outra. Então, pode-se compreender que Ana e Jorge não têm a consciência das questões que afligem a dinâmica do seu sistema nuclear, e que influenciam seus filhos. Complementando essa idéia, Bradt in Carter e Mc Goldrick (1995, p. 211; 220) relata que a superproximidade existente nos relacionamentos pais-crianças geralmente resulta no preenchimento de vácuos existentes de perdas importantes, podendo ser de relacionamentos de gerações anteriores. Isso gera sobrecarga nos relacionamentos parentais e falta de clareza da sua origem. Os filhos podem ser usados para preencher um vazio na vida dos adultos por diversos motivos, sendo freqüentemente pela perda dos próprios pais, da falta de intimidade conjugal ou da falta de participação em outras esferas de vida que não seja a doméstica, seja por simples opção ou devido a fracassos. Isso reafirma que Jorge repete seu antigo sistema familiar, onde ele se apega à filha, que é abandonada e rejeitada, por ele ter sido rejeitado por sua mãe, e também devido ao fato do casal não ter estabelecido uma intimidade.

Cada gravidez ocorre de formas diferentes, com demandas desiguais. Para Prado (1996, p. 101), filhos de uma mesma família têm destinos e expectativas diferentes. É preciso entender as relações familiares e o contexto em que ocorre 0 nascimento. Os pais não são os mesmos para cada filho ao longo do ciclo familiar. Dessa forma, os filhos também não são os mesmos para os seus pais, de acordo com o sexo, idade, características genéticas, etc. Cada uma dessas características interage de forma diferente com o casal, correspondendo ou não as expectativas.
Numa terapia só é possível rever a problemática trazida pela família a partir da modificação do significado atribuído ao comportamento sintomático do paciente. Este comportamento deve ser avaliado como uma forma de adaptação, falhas da comunicação, nas redes relacionais e não como reflexo de uma fraqueza individual (Andolfi, Ângelo, Menghi, Corigliano, 1984, p. 44 \& Elkaim, 1998, p. 216).

Por outro lado, Reyna e Trujano (2000, p.05) citam que a indicação do sintoma como pretexto é o que evidencia que ainda faz falta muita informação necessária para resolver o problema ou que é um passo inicial para seu controle definitivo. Neste caso, a queixa inicial em terapia era um distúrbio alimentar em Jaqueline, que logo em seguida se despotencializa e o enfoque se faz presente no casal. O fardo que a criança carrega consigo é extremamente pesado, pois sobre ela estão lançadas as expectativas de seus pais para a resolução de seus próprios problemas. Elkaim (1998, p. 203) cita que a maneira como o paciente percebe a realidade de suas interações contribui para a manutenção de suas dificuldades, atualizando condutas diferentes, sendo essas que possibilitam as mudanças. Os aspectos cognitivo e comportamental definem as duas grandes categorias de intervenções terapêuticas: as injunções comportamentais e as técnicas de redefinição. Toda mudança significativa gerará uma resposta na pessoa que visa restabelecer (ou manter) um estado satisfatório.

De acordo com Elkaim (1998, p. 196), no início de um processo terapêutico é necessário que o psicólogo trace seu diagnóstico a partir de algumas identificações: quem é o paciente (quem sofre mais com a situação e está mais disposto a modificá-lo, podendo ser também quem reforça a homeostase); qual é o problema (o terapeuta não aceita simplesmente a história contada, mas busca as informações sobre a maneira de pensar dos envolvidos e como eles se relacionam); quais as tentativas feitas para lidar com o problema (informações sobre os recursos que a família possui, quais as características mais comuns dessas tentativas e o que fazem para evitálas); qual é o objetivo mínimo (objetivo concreto que se deseja buscar).

\footnotetext{
9 Duplo vínculo são as falhas ocorridas na comunicação, com antagonismo, onde, muitas vezes, a comunicação verbal não condiz com a não verbal.
} 
Numa terapia, o principal objetivo é auxiliar as pessoas a solucionarem os seus problemas mediante algumas modificações que lhes permitam optarem por outras formas de resolução de seus problemas, em vez de continuarem recorrendo às mesmas tentativas anteriores. Outro objetivo é fazer com que percebam de maneira diferente a situação da problemática. Para isso é necessário haver calma e respeito ao tempo de adaptação do paciente (Reyna \& Trujano, 2000, p.10). O psicólogo que trabalha na abordagem sistêmica não avalia prioritariamente o sintoma do sujeito, mas sim o que faz ocasioná-lo e as relações que o mantém. Dessa forma, a doença deixa de ser considerada conseqüência de um psiquismo individual perturbado, mas sim um problema de comunicação surgido no interior da célula familiar. A pessoa que apresenta o sintoma, nessa visão, não é visto como doente, mas como o "bode expiratório" da família, o que demonstra à sociedade os problemas envolvidos nessa interação. Para trabalhar com esta questão é necessário modificar a estrutura relacional do sistema familiar, enfatizando menos a origem do problema e o conteúdo trazido pela família. $\mathrm{O}$ fato essencial é a estrutura atual e a relação entre eles. A maior dificuldade é fazer com que os membros do sistema se comportem de maneira diferente para modificar as interações, de tal forma que o sintoma se torne inútil ou inadequado. É priorizado o que as pessoas fazem e não como interpretam as suas próprias ações. É preciso que a família consiga focar o problema presente, bem como o terapeuta avaliar a dinâmica familiar e os recursos utilizados para a resolução da questão e mostrar a direção da mudança desejada (Elkaim, 1998, p. 196- 197).

É preciso estar atento para o fato de mudar as idéias das pessoas representa colocar em perigo seus conceitos sobre si, sobre os outros e sobre o que a cerca. E todo esforço do terapeuta que vise modificar o sistema de pensamentos acarretará, portanto, reações de defesa, contra-argumentos, etc., isto é, retorno ao sistema habitual (Elkaim, 1998, p. 208). Então, um processo intervencionista no caso Jaqueline deve considerar essas possibilidades de mudanças, não deixando de lado o aporte emocional das pessoas individualmente e como grupo, para que o sistema entre novamente em homeostase, tendo resolvido suas questões.

\section{Referências}

Andolfi, M., Angelo, C., Menghi, P., \& Nicolo Corigliano, A. M.(1984). Por trás da mascara familiar: Um novo enfoque em terapia da família. Porto Alegre: Artes Médicas.

Carter, B., \& Goldrick, M. C (1995). As mudanças no ciclo de vida familiar: Uma estrutura para a terapia familiar. (2a ed.) Porto Alegre: Artes Médicas.

Elkaim, M. (1998). Panorama das terapias familiares. São Paulo, SP: Summus.

Ponciano, E. L. T. (2002). Família Nuclear e terapia de família: conexões entre duas histórias. Revista Estudos e Pesquisas em Psicologia, 2(2). Recuperado em agosto de 2005: http:// www2.uerj.br/ revispsi/v2n2/ sumariov2n2.html

Ponciano, E. L. T., \& Feres-Carneiro, T. (2003). Modelos de família e intervenção terapêutica. Revista Interações do Programa de Pós-graduação em Psicologia da Universidade São Marcos, 8(16).

Prado, L. C. (1996). Famílias Terapeutas: construindo caminhos. Porto Alegre: Artes Médicas.

Reyna, J., \& Trujano, R. (2000). Terapia familiar sistemica: el modelo interaccional y su aplicación a un caso de ansiedad. Revista Eletrônica de Psicologia Iztacala, 3(1). Recuperado em agosto de 2005. http://www.iztacala.unam.mx/ carreras/psicologia/psiclin/principal.html

Satir, V. (1980). Terapia do grupo familiar (2a ed.). Rio de Janeiro, RJ: Livraria Francisco Alves.

Recebido em/Received in: 22/05/2006 Aprovado em/Approved in: 19/06/2006 